\title{
A VIOLÊNCIA “MOVE O HOMEM": ABORDAGEM CLÍNICA DE UMA SUBJETIVAÇÃO TRANSMASCULINA ${ }^{46}$ \\ VIOLENCE “MOVES THE MAN": CLINICAL APPROACH OF A TRANSMASCULINE SUBJECTIVATION ${ }^{47}$
}

\author{
Nicolas Evzonas ${ }^{48}$
}

\begin{abstract}
RESUMO
Diante da invisibilidade das transidentidades FtM (female-to-male) na bibliografia científica e nas representações culturais, o autor constrói a monografia de um indivíduo que deseja modificar o gênero feminino atribuído a ele em seu nascimento. Ele desenvolve, assim, as múltiplas violências - intrapsíquicas, familiares, sociais e clínicas - que participam da dinâmica da subjetivação de gênero. A interrogação em torno da contratransferência do(a) terapeuta revela-se central no contexto de todas essas violências acumuladas.

Palavras-chave: Maternidade. Violação. Esterilidade. Transgênero. Contratransferência.
\end{abstract}

\section{ABSTRACT}

Faced with the invisibility of female-to-male (FtM) transidentities in scientific literature and cultural representations, the author builds the monograph of an individual who wishes to modify the female gender attributed to him at birth. He thus develops the multiple violence - intrapsychic, familial, social and clinical - that participates in the dynamics of gender subjectivation. The questioning about the therapist's countertransference is central in the context of all this accumulated violence.

Keywords: Maternity. Violation. Sterility. Transgender. Countertransference.

\footnotetext{
${ }^{46}$ Tradução de Profa Mônica Fiuza BF (coordenadora), Rafael Rodrigues (discente) e Thainá Carungaba (discente) - LABESTRAD - UFF; Revisão de Marília Etienne Arreguy - Professora Associada I- Universidade Federal Fluminense - UFF.

${ }^{47}$ Texto em francês publicado pela Revista ERES | "Psicologia clínica e projetiva" (C) ERES. ISSN 12655449/ISBN 97827496434

${ }^{48}$ Doutor em Letras, psicólogo clínico, pesquisador em psicanálise da Universidade de Paris, CRPMS (Centro de Pesquisa em Psicanálise, Medicina e Sociedade). Nicolas Evzonas atualmente trabalha no Centro de Pesquisa Psicanalítica, Medicina e Sociedade "(CRPMS) EA 3522, da Universidade Paris Diderot. Nicolas pesquisa em Psicanálise e Psicologia Clínica. Seus interesses atuais se concentram em identidades trans, contratransferência e interseção de metapsicologia, sociologia, estudos feministas e teoria de gênero. E-mail: nicolas.evzonas@gmail.com
} 


\section{RevistAleph}

\section{INTRODUÇÃO}

Se o transexualismo é um fato recente ligado à tecnosfera moderna, a transidentidade, que engloba a diversidade das identidades trans, descreve um fato cultural mais vasto e presente em todas as sociedades e em todas as épocas. Tratandose da cultura ocidental, identificam-se as origens das metamorfoses de sexos no pensamento mito poético da Antiguidade greco-romana, com os casos emblemáticos de Iphis, que se torna menino para poder amar uma jovem, de Caenis, que se transforma em um guerreiro imbatível para se vingar do ultraje de seu estupro, de Tirésias, transformado em mulher por ter atacado a fêmea de um casal de serpentes, antes de retornar a sua antiga natureza após ter agredido o macho. As referências multiplicamse quando se expande a noção de metamorfose, incluindo a apropriação de traços socialmente atribuídos ao outro gênero. Citemos, em relação a isso, o ilustre exemplo das Amazonas, guerreiras que mutilavam um seio, para não serem incomodadas quando atirassem de arco e flecha.

Na exuberante bibliografia científica consagrada ao "transexualismo", percebese uma escassez impressionante de estudos sobre as mulheres desejosas de se "transicionarem" em homem. A mesma carência pode ser observada nas biografias dos trans, na indústria cinematográfica e televisiva. Esforçando-se para compreender essa particularidade, Lothstein (1983) estabelece a hipótese de uma hostilidade inconsciente em relação aos trans FtM (Female-to-Male [mulher-para-homem]), que constituiriam uma ameaça para a autoridade masculina, levando-se em conta os paradigmas androcentristas de nossas sociedades ocidentais, ao passo que Califia (1997, p. 34) reforça "a dissimetria do olhar lançado sobre os dois sexos no âmbito de nossas sociedades heteronormativas".

Percebemos que o termo "transexualismo" foi inventado pelo psiquiatra Américain Cauldwell (1949), para descrever, exatamente, o caso de uma menina que desejava se tornar menino. Não é, então, significativo, que a associação entre a gênese dessa denominação e as mulheres com vocação masculina seja eludida na bibliografia especializada? Esse lapsus memoriae não demonstra a contrário a obsessão pela emasculação? Se pudéssemos evocar, como explicação para o desinteresse pelo 


\section{RevistAleph}

"transexualismo feminino", a menor visibilidade de trans FtM no passado ou as faloplastias quase nunca aptas a garantir um pênis funcional, análogo ao membro bioviril, argumentaríamos que a razão homens/mulheres trans tende a se equilibrar hoje em dia (Hansbury, 2005; Peretti, 2009; Chiland, 2011) e, em relação à percepção das transgenitalizações imperfeitas, poderíamos inferir a hegemonia do genital e a obnubilação pelo falo desenvolvendo sua potência erétil. A psicanálise, que claramente não escapa a sua inserção no socius, confirmaria, por seu seletivo mutismo sobre o "transexualismo feminino", a reprodução dessa lógica hétero-falo-centrista.

É nesse contexto de carência representacional que se insere a presente contribuição. Nossa iniciativa visa esclarecer certos aspectos das infinitas variações do que, doravante, convirá chamar transidentidades FtM ou identidades transmasculinas. Diante de um "psicanalismo" (Castel, 1973) inclinado a metapsicologizar o gênero, deturpando sua dialetização com o social, e de um sociologismo, ou mesmo um "societalismo" (Sénac, 2017) surdo às implicações inconscientes e à conflitualidade psíquica inerentes à identidade de gênero, nossa abordagem, que se afirma transepistemológica, levará em conta, simultaneamente, a dinâmica familiar e intrapsíquica, assim como as questões socioculturais que fazem parte desse tipo de subjetivação.

Ao contrário dos Gender Studies que definem o gênero como uma simples formação discursiva e uma pressão social interiorizadas pelo sujeito de maneira passiva, nossa clínica, que encontra eco no quadro conceitual desenvolvido por Laplanche (2003a), incita-nos a concebê-lo como uma categoria psíquica, sem resultar diretamente de uma relação de poder entre sociedade e indivíduo, mas de um trabalho psíquico efetuado pelo infans ${ }^{49}$ que traduz ativamente uma série de mensagens enigmáticas de endossamento emitidas pelo adulto e compromissadas por seu inconsciente sexual. A imagem escolhida por Laplanche (2003b) para exprimir o efeito dessas mensagens vindas de fora e que suscitam uma verdadeira identificação pelo ${ }^{50}$ outro é a da implantação, ou mesmo da intromissão no Eu corporal, evocando a inscrição violenta da norma retratada por Butler $(1993,2006)$. Apesar da diferença da concepção

\footnotetext{
${ }^{49}$ N.T.: Criança pequena, infante.

${ }^{50}$ N.T.: Itálico no original.
} 


\section{RevistAleph}

butleriana, segundo Laplanche (2003a, p. 168), "é o pequeno grupo de socii próximos que inserem a criança no social, não é a Sociedade que determina". O círculo social imediato é o que introduz a criança no universo do "mitossimbólico", isto é, apresentaa a imagens ou narrativas culturais, que constituem ora uma ajuda, ora um obstáculo, para a tradução de significantes enigmáticos (Laplanche, 2003b). Em outras palavras, as prescrições socioculturais de gênero não são diretamente incorporadas pelo sujeito, mas previamente mediatizadas pelos primeiros provedores dos cuidados da criança e, no momento crucial, a adolescência, da destradução-retradução desses códigos, pelo grupo de pares (Dejours, 2018). A visão metapsicológica reúne, assim, os postulados dos Gender Studies: o "Eu" dotado de gênero constitui uma resposta ao que vem do outro. Sendo nosso principal objetivo a otimização das modalidades para se ter responsabilidade em relação à população trans, inferiorizada pelas normas dominantes e pela atitude aterradora de muitos profissionais da saúde mental, como narram, sistematicamente, nossos pacientes, daremos destaque em nossa demonstração à contratransferência do(a) clínico(a). Nossa iniciativa insere-se em uma vontade de reforçar a reflexividade crítica da psicanálise que, por muito tempo, 'patologizou' as transidentidades, através de "injúrias diagnósticas" (Ayouch, 2015), produzindo, às vezes, subjetividades adoentadas pelo poder performativo das palavras (Butler, 1997). É por isso que nos absteremos da ideia de qualquer debate em torno de um diagnóstico psicopatológico, em benefício de uma discussão acerca dos processos de subjetivação.

Insistiremos, ao longo deste artigo, na noção primordial de pressão (Buttler, 2006) ou de efração traumática inerente à implantação de mensagens sexuais e de assignação de um gênero pelo outro:

A tradução da mensagem enigmática adulta não ocorre de uma só vez, mas em dois tempos. O esquema em dois tempos é aquele mesmo do traumatismo: no primeiro tempo, a mensagem é simplesmente inscrita, ou implantada, sem ser compreendida, como se fosse mantida sob a fina colcha da consciência, ou "sob a pele". Em um segundo tempo, a mensagem é revivificada. Ela age, então, como um corpo interno, sendo preciso, a qualquer custo, integrar, dominar. (Laplanche, 2003b, p.200) 


\section{RevistAleph}

Essa visão justificará o título de nossa contribuição, "a violência move o homem", que faz alusão ao conceito lacaniano de "empuxo-à-mulher", aplicado ao "transexualismo" de Schreber (Lacan, 1973), que redirecionaremos e explicitaremos em nossa conclusão.

A violência inerente às injunções de gênero será revestida de um valor paradigmático na narrativa de uma mulher com identificações transgêneras, que acolhemos na instituição, no âmbito de entrevistas clínicas individuais de visão terapêutica. Expliquemos que esta, que utiliza o pronome feminino para falar de si mesma, e que chamaremos a partir de agora de Ruslana, nos foi encaminhada, devido a um sofrimento induzido pelas brutalidades cometidas por seu marido. Se a narrativa de Ruslana pode parecer eminentemente singular aos olhos de terapeutas, sem citar as clínicas do extremo, ela apresenta, na verdade, diversas similaridades que pudemos recolher da parte de trans, vindos(as) principalmente do meio da prostituição. É por isso que nos autorizamos a inserir em seu relato alguns elementos oriundos das histórias de outros(as) pacientes confrontados(as) por problemáticas análogas sem, no entanto, fazer delas exemplos correlatos, nem um modelo inclusivo do transgenerismo FtM, do qual, aliás, contestaríamos qualquer possibilidade. Essa forma de escrever pareceu-nos ideal para preservar, de uma só vez, o anonimato e a singularidade desse caso que revela, sem filtro e em um grau superlativo, como uma lente de aumento, as agressões familiares, societais e clínicas sofridas de forma recorrente por indivíduos não binários ${ }^{51}$.

\section{A VIOLÊNCIA DO AMBIENTE FAMILIAR}

\section{A condenação do 'desengendramento' e impulsos infanticidas}

Assim que chegou diante de nós, Ruslana fez a confissão nodal, que atravessou todas as sessões subsequentes, a respeito de sua hostilidade com as crianças. Citemos seu enunciado inaugural: "Eu detesto meu corpo de mulher; não teria suportado que

\footnotetext{
${ }^{51}$ Na bibliografia internacional, "não binário" (non binary) ou "genderqueer" constitui uma categoria genérica que agrupa as identidades e expressões de gênero não normativas: andrógenos, agêneros, trigêneros, genderfluid (gênero fluido), etc.
} 


\section{RevistAleph}

um bebê saísse desse corpo; teria preferido comê-lo e beber seu sangue". Ruslana continuou a retratar, ao longo das sessões, a violência que surge nela quando vê criancinhas na rua. Ela sente a tentação de "matá-las", de "explodir seus miolos", de "arrancar seus corações", mas ela se contém. As convocações ao tribunal, em razão de suas desavenças judiciais, ajudam-na a não ceder a seus impulsos, pois the dão esperança de que, para obter o divórcio de seu "marido execrável", a justiça a ajudará. O marido, segundo seu discurso, um homossexual mal assumido, que tentou impor-lhe à força o uso do véu islâmico, a "despedaçou", a "tratou como lixo" e fez dela uma "mulher-privada". Apoteose da vergonha: ele é pai de um "bastardo sujo", que ela sonha exterminar e, além do mais, agora, ele se esquiva para evitar as despesas da dissolução legal do casamento.

Ela declara que seus impulsos infanticidas têm origem no ultraje que constitui para ela a existência de um filho de seu marido, embora tenhamos lembrado que, ao longo dessas associações, ela havia mencionado que, muito jovem, havia virado uma mesa em um bar, para calar algumas "criaturas diabólicas de seis anos" que a chamavam de "puta". Ela admite, então, que seus problemas com crianças datam, efetivamente, de muito tempo atrás e evoca a lembrança dolorosa de um aborto sofrido no passado, aos quatro meses de gravidez. Ela declara que seus sogros a obrigaram a suportar essa "terrível mutilação", pois seu companheiro, a quem queria bem, já era pai. Ruslana voltou a esse assunto ao longo de outra sessão, para admitir que a decisão de interromper sua gravidez havia sido tomada sob a pressão de problemas financeiros. Em uma outra ocasião, ela explicou seu aborto tardio: "Eu assinei e consenti o risco de morte". Em todo caso, ficou claro, o suficiente para nós, que o ódio por crianças tocava um substrato traumático de sua história pessoal, com raízes em um passado resolutamente longínquo.

No decorrer da terceira sessão, Ruslana falou de sua mãe, "uma grande depravada", que um dia havia Ihe pedido que fizesse um cunnilingus, "uma verdadeira vadia que todo mundo chamava de 'a gostosona do vilarejo'", que havia ido para o exterior gravar filmes pornográficos, "jogando" sua única filha aos avós. Ruslana lembrase de ter descoberto, quando tinha cinco anos, "uma fita cassete mostrando as sem- 


\section{RevistAleph}

vergonhices da mãe". A sexualidade indiscutivelmente violenta dessa mulher e o clima incestuoso que ela cultivou nos remetem à variante violenta da implantação de significantes enigmáticos esboçados por Laplanche (1990, 2003b): a intromissão, que desconsidera o processo tradutivo e seu caráter repressor, aniquilando significantes, sem nenhuma metabolização, através de uma transmissão intergeracional ${ }^{52}$. Nessa perspectiva, o Eu corporal de Ruslana teria recebido de sua progenitora a inscrição violenta de uma pulsionalidade bruta, transbordante, que permaneceu intraduzida e, assim, não conectada e nem simbolizada.Outra informação nos pareceu importante: Ruslana relatou, com um espírito de revolta e raiva, que sua mãe lhe acusara de ter estragado seu corpo ao nascer, dizendo, inclusive, que deveria ter abortado. Ao mesmo tempo, essa mãe expressou o desejo de ser um modelo para a filha, o que configura traços de uma "injunção paradoxal" (double bind). Daremos destaque a essa “condenação de desengeneramento" (Le Poulichet, 2010) que nossa paciente conserva na memória, indissociável da destrutividade "implantada" pelos significantes maternais. Se Ruslana repete sempre que fez um "pacto com o diabo" e que é "feita para o mal", esta afirmação não reproduz, no fundo, a fala aniquiladora gerada pelo narcisismo ilimitado de sua mãe? E as tendências infanticidas não poderiam ser entendidas como o ódio de Ruslana em relação à infans, nascida da introjecção do enunciador-agressor encarnado pelo Outro parental?

Nessa ótica, a "terrível mutilação" do aborto, que ela recebe, ora como imposto pelos outros, ora como uma assinatura pessoal (incitação interna), confirmaria o sentido de uma realização do desejo mortífero maternal ("eu deveria ter abortado"). Como consequência, Ruslana teria sido impulsionada a interromper tardiamente a gravidez e a condenar seu feto à inexistência, se "mutilando" para repetir o que sua mãe havia feito com o escalpelo de sua fala deletéria. Esta hipótese une-se à repugnância expressa

\footnotetext{
52 Diz respeito à dimensão da transmissão intergeracional dos significantes enigmáticos abordada no "modelo tradutivo" de Laplanche. Cf. a hipótese formulada por Andreyev \& Neau (2017, p. 241), segundo a qual "a traduzibilidade das mensagens maternais dependerá da maneira pela qual a mãe terá 'traduzido' seus próprios conflitos infantis". Seria interessante, por esse ponto de vista, confrontar as teorias laplanchianas sobre a transmissão das mensagens no "mandato familiar" concebido por Lebovici (1989), o qual seria transmitido ao bebê, conforme os devaneios conscientes e pré-conscientes de seus pais, sustentados pela "criança imaginária" que assombra seus espíritos e seus desejos inconscientes, cristalizados na "criança fantasma" que habita neles.
} 


\section{RevistAleph}

no início, em relação a seu corpo de fêmea, que ela teria preferido manter longe de qualquer trabalho de parto. Tomada pela percepção parental da maternidade como a morte da feminilidade, Ruslana parece execrar seus traços femininos, por seu potencial maternal e fecundante. É por isso que cogita realizar uma histerectomia total?

\section{As violências acumulativas e o "magnum votum"}

Ruslana evocou sua infância com os avós. Sua avó é retratada como uma mulher cruel, infligindo castigos corporais à neta, quando esta não obedece às regras da avó. Seu avô aparece como uma figura sedutora que ensina esgrima a Ruslana, com sabres confeccionados por ele, experiência iniciadora que suplantará o amor que a neta, antes, tinha pelas bonecas. Ele a leva consigo aos estaleiros onde trabalha e a trata "como um homem de verdade". Ele, além disso, é inventivo e fabrica sua própria bebida alcóolica. Essa imagem cheia de ênfases idealizantes não tarda a revelar seu oposto assustador. Esse maravilhoso avô é também um selvagem que, sob o efeito do álcool que consome imoderadamente, espanca a esposa a golpes de pá de ferro ou martelo e tenta, repetidas vezes, afogá-la na banheira. Ruslana se intromete para salvar sua avó e, "acidentalmente", também recebe golpes. Ela diz que seu avô jamais quis machucála, ainda que algumas vezes tenha lhe acontecido de desmaiar em um banho de sangue, após essas surras "casuais". Inútil insistir sobre as racionalizações frágeis que servem para proteger seu torturador, conforme funcionamento do mecanismo de identificação com o agressor. Sua idealização — os trabalhos de Klein defendem esse argumento lutaria contra a angústia da morte, reminiscência da defesa primitiva contra a busca por um seio deletério, reativada nesse contexto de ameaça e ataque mortíferos ${ }^{53}$. Ruslana preserva, além disso, a lembrança dos quartos separados de seus avós. Ela não consegue lembrar de algum momento em que o casal dormira junto, pois era ela que tinha seu lugar reservado ao lado da cama de sua avó. Pareceu-nos interessante que, no momento da narrativa, a evocação das camas distantes de seus avós a levara a uma

\footnotetext{
${ }^{53}$ Klein (1957, p. 34) destacou que o "objeto bom" está muito integrado no Eu e forma a base do amor e da segurança, enquanto o seio bom "demais", antes dito o seio idealizado, deriva da pulsão de morte e constitui uma defesa contra a angústia persecutória.
} 


\section{RevistAleph}

associação com seu vegetarianismo. Quando perguntamos sobre sua repugnância por carne, ela começou a descrever certas cenas de abate de animais assistidas na infância. As imagens de sangue jorrando, de entranhas espalhadas pelo chão e os gritos das criaturas agonizantes, antes dos avós carrascos abaterem-nas, ainda a assombram e a impedem de tocar em carne. Prefere consumir vegetais e se mostra, aliás, extremamente vigilante a respeito de sua alimentação, pois seu objetivo é tornar-se um "guerreiro magro de músculos sarados".

Em nosso ver, o relato de Ruslana deixa transparecer uma cena primitiva de violência inusitada, transposta sobre animais e negada pela lembrança da imagem dos quartos separados do casal "parental". Pode-se pensar que a identificação insuportável com a presa ensanguentada, suscitando horror, favoreceu a introjeção dos agressores, próximos da figura monstruosa de pais misturados e, definitivamente, a contra identificação com os animais sacrificados. Rechaçar a carne não sugere a exclusão de uma comida inassimilável, impossível por si só?

É interessante notar, além disso, que a imagem ideal de virilidade que Ruslana projeta de si mesma ("um guerreiro magro de músculos sarados") remete ao retrato de seu avô-abatedor, esboçado, assim, em outra sessão: magro, forte, musculoso, "sarado", esgrimista e bebedor de álcool "vermelho". A esgrima, evidentemente, tem eco nos combates de sabre que tanto encantaram Ruslana, instruída por seu avô na arte de ser um homem "de verdade", e o álcool vermelho ecoa na sua autodescrição como vampira. Se acrescentarmos a esse quadro a condenação do 'desengeneramento' feito pela progenitora, que a conduz a uma contra identificação feroz de tudo o que representa (maternidade, feminilidade, sexualidade), podemos começar a compreender o funcionamento psíquico que sustenta as vocações transidentitárias de Ruslana.

Após o falecimento dos avós, nossa paciente viveu com a mãe e o padrasto, este também retratado como um homem violento. Ruslana evoca uma cena de tentativa de assassinato contra ela ("ele tentou me matar me atingindo com seu carro enorme"), fato que provocou sua saída definitiva do teto maternal. Segundo uma versão diferente desse episódio narrado em outra ocasião, a então adolescente teria partido 


\section{RevistAleph}

por medo de ser violentada. Serão evocadas, aqui, as alusões esparsas e frequentes à consanguinidade considerada como o pior dos crimes: "É melhor ser um vampiro, um canibal que ataca crianças, do que praticar o incesto". Se lembrarmos do "temor do colapso", que se interpõe ao colapso que já ocorreu, como Winnicott (1989) ilustrou, podemos nos perguntar se o medo expresso por Ruslana de sofrer o incesto não confirma uma significação similar. A tentativa do padrasto de matá-la, "atingindo-a" com seu "carro enorme", não poderia constituir uma confissão em meias palavras de um estupro vivido como uma experiência mortífera?

Tendo deixado a casa da família aos dezesseis anos, Ruslana optou por se instalar na cidade, para se tornar stripper: O corpo ultrajado cobre-se de lantejoulas e se oferece ao olhar de todos, por vontade própria e segundo suas próprias regras. Porém, uma noite, no momento em que ela volta da boate onde se apresentava, um episódio dramático aconteceu:

Fui estuprada e sequestrada e, desde então, minha parte mulher morreu. Decidi virar homem. Fiz strip-tease exibindo meu corpo de mulher, mas era uma fachada. Com meu marido e alguns amantes, deixei em suspenso meu desejo de me tornar homem. Enfraqueci, virei mulher. Bateram-me, humilharam-me, forçaram-me a amar o Islã, fui feita de privada, de lixeira. Agora acabou. Preciso cortar os seios, arrancar meu útero e colocar um pênis, mesmo que não confie nos médicos.

Esse relato, que muito nos transtornou, nos remeteu ao mito de Caeneus, representado por Ovídio em Metamorfoses (XII,150-209): Moça famosa por seus atrativos, Caenis é estuprada por Netuno que, vendo-a desesperada, concede-lhe um pedido, qualquer que seja. "Tal violação a minha honra, responde Caenis, apela por / Um voto extremo [magnum votum]: que eu não possa mais sofrer nada como tal; faça com que eu não seja / Mais mulher e ficarei plena". O deus dos mares, então, transforma Caenis em Caeneus, metamorfoseando-a em um homem imbatível e impenetrável a golpes de lança.

Tanto o relato de Ruslana quanto a narrativa ovidiana corroboram explicitamente um padrão, que percebemos em algum(umas) trans FtM que acompanhamos: a violência "impulsiona para o outro" gênero. Não obstante, essa 


\section{RevistAleph}

violência que, desesperadamente, apela por reparação "extrema" [magnum] - a invulnerabilidade e impenetrabilidade do corpo ultrajado - participa de uma dinâmica infinitamente mais complexa. No caso de Ruslana, o sentido de seu sequestro e estupro está incrustado nas significações de uma série de mensagens enigmáticas que lhe foram violentamente implantadas por seus familiares próximos, desde a infância. Se sua parte mulher está morta, como afirma de forma comovente, é porque o atentado sexual reativou a mortificação de sua feminilidade, inicialmente realizada pelas palavras nefastas da mãe, assim como os ultrajes que sofreu quando criança: as brutalidades do avô e o incesto do padrasto.

A significação desses ultrajes, reavivados pelos maus tratos de seus parceiros machos, inflama-se no momento crítico em que seu marido bárbaro procria com uma rival, o que confere uma potência irreprimível ao desejo de 'transmasculinização'. Este desejo, latente desde a infância, marcado pelo feliz parêntese das brincadeiras de espada com o avô, é estimulado, segundo nossa hipótese, pela introjeção de seus agressores, pela contra identificação com uma mãe intoleravelmente excitante, pelo contra investimento de uma avó invariavelmente brutalizada e vitimizada e pela identificação com um avô idealizado, que Ihe instruíra na arte de ser um homem "de verdade". Pode-se pensar que a vocação 'transidentitária' de Ruslana, assim como de outros(as) trans FtM abalados(as) por uma violência 'passivante' e atravessados(as) por 'assignações' específicas de gênero, indissociáveis dos desejos inconscientes de seus familiares próximos, possuem o valor de uma defesa antitraumática.

Mencionemos, além disso, o desejo, reiterado por Ruslana ao longo das sessões, de se transformar em um guerreiro vigoroso, que exterminará o Islã e massacrará as crianças, em alternância com o desejo de se tornar um padre devoto à abstinência sexual e ao sacrifício de animais sagrados. Esses temas centrais retomam sua história subjetiva com grande precisão e, provavelmente, visam reparar, um após outro, os "traumas cumulativos" (Khan, 1963) que marcaram sua existência. 


\section{RevistAleph}

\section{A VIOLÊNCIA DAS NORMAS}

\section{Do estigma da esterilidade à construção de uma transidentidade ex-cêntrica}

Diferente de outros transgêneros FtM, Ruslana não demonstrava nenhuma aversão em relação a sua feminilidade "orgânica", com exceção do horror de ver uma criança sair de seu corpo. Ao escutá-la atentamente, pudemos notar sua repugnância em desempenhar um determinado papel feminino bem definido: "Não faz o meu tipo ser dona de casa, ficar presa dentro de casa, obedecer ao marido, criar filhos e fazer o que a sociedade espera de mim". Nossa atenção deteve-se em sua frase seguinte, que surgiu em seu desabafo contra o esposo que havia procriado com outra: "Eu, ficar mulher estéril, enquanto ele está com outra e uma criança que terá o mesmo nome que eu?" Parece que nossa paciente anunciou uma experiência de desapropriação ligada a seu fracasso em se tornar mãe e a degradante assimilação com uma "esposa infecunda".

Antes da separação, Ruslana e seu marido compartilhavam, com liberdade e sem complicações, suas aventuras extraconjugais - o que indica que a questão da fidelidade não era a origem da revolta de nossa paciente - , até o momento fatídico do surgimento do "bastardo sujo que veio abalar tudo". Ruslana defendia que esse filho ilegítimo havia ultrajado suas crenças religiosas católicas, principalmente o ritual de seu batismo, ou seja, sua nominação e identidade. O verdadeiro desafio era, a nosso ver, seu sentimento de humilhação diante de uma concubina fecunda, apta a cumprir o destino da feminilidade de acordo com um preceito cultural - uma narrativa mitossimbólica mediada pelo socius ao redor, segundo Laplanche (2003b) - , onde tem origem sua hesitação como mulher. É muito significativo que Ruslana, que se definia como bissexual, tenha frisado que tinha relações sexuais com homens e transgêneros $M t F$, mas "jamais, em nenhuma circunstância, com mulheres de verdade", manifestando um desgosto semelhante ao que sentia em relação a sua rival fértil. Seria útil lembrar que os transgêneros $M t F$ são mulheres construídas e, portanto, infecundas. Para nós, ficava bastante claro que a raiva em relação à amante de seu marido traduzia uma inveja nascida de uma autopercepção de insuficiência diante de um ideal feminino consubstancial à aptidão procriadora. 


\section{RevistAleph}

A dependência de Ruslana em relação a estereótipos tradicionais aparecia por trás de uma narrativa pontuada por excessos de sexo, droga e vida urbana moderna. Tal clichê ficou perceptível enquanto ela nos contava que havia se prostituído por um curto período, para ajudar financeiramente o esposo encarcerado: "Uma mulher normalmente deve ser sustentada. Como era eu quem pagava suas despesas, quer dizer que meu marido delinquente não era mais um homem. Ele era, na verdade, minha puta!" Esta declaração descreve, admiravelmente, a maleabilidade discursiva do gênero. Nossa paciente era, de repente, uma ardente adepta de certas normas arbitrárias sobre a "essência" do masculino e do feminino.

Além disso, Ruslana relatou, diversas vezes, que não podia encontrar seu lugar na sociedade, tendo em vista sua personalidade e seu físico atípicos. Suas roupas excêntricas, sua maquiagem extravagante, sua musculatura saliente valiam-lhe zombarias e palavras humilhantes. Ela evocou, como exemplo, um episódio pelo qual passara em uma boate de strip-tease: os recrutadores não a aceitaram, pois, para eles, ela parecia um "travesti", o que Ruslana tomara como uma injúria. Exasperada pelo conservadorismo reinante, passou a frequentar o meio homossexual, na esperança de encontrar mais tolerância e abertura. Ao invés disso, encontrou parceiros que a maltratavam, ridicularizavam suas origens e crenças religiosas, agrediam-na até sangrar e a cobriam de insultos. Além disso, no meio heterossexual, ela continuou a sofrer discriminações: foi demitida do trabalho porque havia participado da "parada da vergonha" - a Gay Pride, e foi sistematicamente tratada como "extraterrestre", "fêmea esquisita", "gótica doida", "puta com maquiagem de maluca", etc., sem jamais ter sido reconhecida em sua singularidade.

A reação de Ruslana a toda essa série de afrontas e rebaixamentos foi a identificação com outro transgênero fantástico chamado "Travi", que esperava incarnar, graças aos hormônios e à cirurgia (mastectomia, histerectomia e redesignação sexual). Quais eram os traços dessa construção? "Eu me imagino homem no nível do meu corpo e mulher no nível do rosto, com uma barba e uma maquiagem artística. Travi é hermafrodita." É possível notar o parentesco entre o insulto "travesti", que evocamos acima, e a denominação "Travi". De forma semelhante, a "masculinidade" do corpo de 


\title{
RevistAleph
}

Travi remete à crítica da musculatura de Ruslana, julgada masculina demais pela direção da boate, enquanto a maquiagem artística parece perpetuar a lembrança da "maquiagem de louca". Travi possuía, além disso, os traços de um "padre gótico abstinente que prega por uma religião original: o casamento entre a igreja católica e a igreja satânica". Identifica-se, perfeitamente, o eco dos ultrajes religiosos sofridos por Ruslana (as zombarias sobre sua fé católica e as tentativas dos parceiros de obrigá-la a se converter ao Islã), como se Travi constituísse uma transfiguração da ridicularização. Além disso, a castidade do padre não se insere como um oposto à injúria de "puta"?

\section{Da melancolia à potência de agir}

Os trabalhos de Butler permitem ver de outro modo a subjetivação transgênera de Ruslana. A filósofa americana escreve:

\begin{abstract}
Receber um nome injurioso nos ofende e humilha. Porém, este nome engloba, além disso, uma outra possibilidade: receber um nome é também receber a possibilidade de existir socialmente, de entrar na vida temporal da linguagem, possibilidade que excede as intenções primárias que motivaram a nomeação. Assim, um nome injurioso pode parecer congelar ou paralisar a pessoa chamada por ele, mas pode também produzir uma resposta inesperada e favorável (1997, p. 22, tradução livre).
\end{abstract}

Um exemplo artístico do poder transfigurador da palavra degradante é citado por Laufer (2016, p. 94): “Genet, em sua obra, mostra bem a arte de transformar a vergonha proporcionada pelos insultos, de reinvestir a abjeção, de dar às posições minoritárias e excluídas uma poderosa forma de agir".

Em seus trabalhos posteriores, Butler articulou bem as potencialidades performativas das palavras com as identificações chamadas transgêneros. Ela sustentou, desde o começo, que não podemos apreender isso "fora do contexto em que são discursivamente reivindicados e claramente enunciados. Porque são invariavelmente ajustados, e também percorridos pelas normas culturais que constituem uma interface entre o interior e o exterior" $(2009$, p. 1). Butler prolonga-se na especulação emitida por Freud em Luto e Melancolia, segundo a qual "ele teria uma 


\section{RevistAleph}

atitude de revolta em relação ao melancólico porque buscaria romper um laço, mesmo que mantendo-o involuntariamente" (2009, p. 27). A queixa melancólica buscaria sua resolução na revolta, porque a agressividade permitiria superar ou vencer o outro. Mas de que outro se trata?

Butler sempre destaca, no caminho de Freud, que o objeto perdido pode ser uma ideia como de nação ou pátria, o que o incita a conceber toda forma de ostracismo como potencial foco de melancolia: "Incluindo a exclusão do regime dominante de gênero, que vem a ser privado de reconhecimento pelas normas dominantes ou ser submetido a uma ignorância sistemática" (2009, p. 29, tradução livre). Nesta ótica, a melancolia, diferente da que é encontrada de forma clássica na clínica, como DavidMénard (2009) nos lembra bem, é apreendida "não como patologia individual, mas como condição produzida e reproduzida pelas privações culturais e sociais sistemáticas" (Butler, 2009, p. 29, tradução livre). Uma vez que as normas produzem uma "desrealização da vida" e que elas se tornam elemento do sujeito, através de uma prática identificatória:

(...) a consequência é que é preciso romper com a lealdade em relação a sua própria desrealização, para que um futuro possa surgir; e esse processo deve ser barulhento e colérico. Portanto, se, em condições de transfobia muito difundidas, o que é perdido repetidamente pelas pessoas transgêneros e o que elas tentam repetidamente obter é um lugar, um nome, um espaço de reconhecimento, então, o desejo do transgênero está ligado à possibilidade de se 'endereçar' e de ser o destinatário desse endereçamento. A perda do lugar, o desejo de um lugar é o que surge nessa cena problemática do 'endereçamento', onde o "você" parece não oferecer reconhecimento, onde há uma queixa, uma raiva que pode ser dirigida para o exterior ou para o interior (2009, p. 31, tradução livre).

No caso de nossa clínica, pudemos verificar, muitas vezes, as teses avançadas por Butler e achamos que o caso de Ruslana constitui sua ilustração paradigmática. Essa pessoa ex-cêntrica (fora do centro) acumulou injúrias e afrontas oriundas de uma sociedade e de uma cultura que celebram certas idealidades (o imperativo da mulher que é mãe, financeiramente sujeitada ao homem, não muito musculosa, nem muito maquiada, nem muito sexualmente ativa) inacessíveis para Ruslana e, ainda assim, 


\section{RevistAleph}

impressas nela de maneira indelével. Buscando se libertar dessas ficções normativas que se tornaram seu me-skin (minha pele), ela estava se torturando, da mesma forma que Héracles esforçando-se para arrancar a túnica envenenada de Nessus, colada em sua pele. Seu desejo de homem transmasculino era, sem dúvida, um combate de emancipação da identificação melancólica, contra as imposições de gênero, objeto 'ideático' e ideal, que devia ser imolado, ao preço da autodestruição.

Entretanto, essa luta impetuosa escondia um potencial criativo e uma fonte de poder. Ruslana reiterou que a Parada Gay era uma verdadeira parada de orgulho, da qual gostava de participar porque ela podia reivindicar publicamente sua diferença e gritar alto e forte seu desejo transgênero a toda uma sociedade que Ihe tinha "cuspido na cara". Aliás, uma vez, ela nos informou que ambicionava, após o término do divórcio, criar "um grupo para os 'trans castigados' e militar contra discriminações dessa população fragilizada. Encontra-se aqui condensado "o poder do agir" (agency) nascido do discurso injurioso e a promessa política da virada violenta da melancolia de gênero, que Butler afirma.

Sobre isso, lembremos o ativista trans, Califa (1997), que defende fervorosamente a ideia de se aproveitar do mal-estar 'transidentitário' ou de torná-lo operacional para efeitos coletivos. De forma similar, os trabalhos teóricos sobre gênero, dos intelectuais praticamente reivindicados ou assumidos como trans, tais como Beatrize Preciado, Kate Bornstein ou Karine Espineira, poderiam ser percebidos como versões sublimadas do recurso melancólico da identificação tipo transgênero. Voltemos então a Butler: "O sofrimento devido à patologização é também o recurso que permite produzir poemas cheios de ódio, poemas proferidos em público e que exigem uma nova capacidade pública de escuta" (2009, p. 33). Ruslana foi uma de nossas pacientes que nos recitou os versos mais agressivos e furiosos em relação aos menos assujeitados à 'norma' do recalcado. 


\section{RevistAleph}

\section{A VIOLÊNCIA DA CONTRATRANSFERÊNCIA}

\section{Do receptáculo da violência a outra testemunha}

Lembremos que Ruslana passara por muito sofrimento provocado pela atitude dos profissionais da saúde mental e, assim, ela tinha uma "pré-transferência" (Guillaumin, 1998) negativa em relação aos "psis". Esta foi diminuindo após a nossa primeira sessão que, provavelmente, inspirou-Ihe confiança. Durante a consulta inicial, ela começou a falar de seu processo de transidentidade, contando que, quando ousava dizer algo sobre o assunto, era confrontada à violência, fazendo especial menção a seu marido e a seu último parceiro, que reagiram a sua fala, submetendo-a a sádicos castigos corporais. Comentou, também, que alguns psiquiatras mostraram-se piores do que seus parceiros, porque eles tinham brutalizado o seu cérebro: "Eles nunca me escutavam. Quando eu thes dizia que queria me tornar homem, diziam que eu tinha um problema mental e me enchiam de medicamentos. Uma vez, fui me jogar da sacada e alguém me segurou. Eu era como um zumbi com todos esses rótulos".

Seria ilusão considerar essa violência psiquiátrica como uma resposta adequada à pulsionalidade transbordante de Ruslana. Além dos ativistas ou intelectuais trans ou pró trans (Califa, 1997; Butler, 2006; Espineira, 2011), vários clínicos denunciaram os maus tratos psicológicos submetidos aos transgêneros nas instituições destinadas "a deixar o outro louco" (Ayouch, 2005; Peretti, 2009; Sironi, 2011; Delcours, 2016). Em nossa clínica, tivemos a oportunidade de nos confrontar repetidamente com discursos semelhantes aos de Ruslana. Citemos o exemplo evocativo de um paciente socialmente bem integrado, que nos descreveu como seu psiquiatra lhe prescrevera psicotrópicos em três ocasiões diferentes: uma vez, depois da narrativa de um trecho de uma obra sociológica que descrevia um rito iniciático de sodomia; uma segunda vez, para o "acalmar" após a leitura de um artigo filosófico sobre pornografia; e uma terceira, como resposta à confissão de seu desejo de mudar de sexo. Sem contar a prescrição, esse transgênero $\mathrm{FtM}^{54}$ ouviu a explicação que ele não era trans porque, de acordo com o expert, "o homem constrói sua experiência a partir do exterior para o interior e a

\footnotetext{
${ }^{54}$ N.T.: Female to Male ("de mulher para homem", em inglês no original) - homem transexual.
} 


\section{RevistAleph}

mulher do interior para o exterior. Então, eu era bem uma mulher pois fazia parte do segundo caso! É alucinante como as pessoas rotulavam coisas sobre mim, sobre o que está no meu interior antes mesmo de eu falar do meu interior". Eis, aí, uma ilustração muito reveladora dos abusos provocados por profissionais da saúde mental que, perante seus pacientes, reativam suas teorias sexuais infantis, sob o véu da cientificidade, e cuidam de sua angústia, prescrevendo anestesia do pensamento. Lembremos, também, de um outro paciente transgênero que nos contou sobre uma pequena má formação de seus órgãos genitais, o que levou sua psicoterapeuta a insistir que isto deveria ser corrigido cirurgicamente, "esse problema desagradável e inaceitável para uma mulher", enquanto a pessoa em questão não tinha exposto claramente nenhuma vontade de realizar tal procedimento. Em outro caso, um homem trans FtM, perfeitamente apto a desenvolver uma neurose de transferência no âmbito de uma terapia face a face, sofreu um "diagnóstico ofensivo" (Ayouch, 2005) de transexualismo psicótico, em um consultório particular. Finalmente, mencionaremos uma paciente que buscava realizar uma mastectomia em um centro de atendimento público da disforia de gênero e que nos confessou o quanto sofrera por ter sido forçada a modificar sua biografia, para que ficasse de acordo com as exigências do protocolo oficial. 0 "sofrimento transexual", tão frequentemente ontologizado e essencializado, não parece, neste caso, fabricado por todo um sistema de poder e de saber médicopsicológico?

Em vista dessas experiências iatrogênicas, da qual esboçamos um contorno sucinto, não é surpreendente que Ruslana esteja alegre por ter encontrado um ambiente pacífico de escuta em um metacontexto institucional seguro e que tenha sentido necessidade de nos elogiar: "Você é o único psi que me compreende. Os outros diziam que sou lunática e me bombardeavam de medicamentos". A liberdade de sua fala foi favorecida pelas nossas intervenções minimalistas, limitadas, frequentemente, à reformulação de seus dizeres e ao destaque de alguns de seus enunciados, para the significar que ela podia obter o que tão cruelmente lhe faltava: ser ouvida.

No decorrer de uma sessão, nossa paciente mergulhou vertiginosamente em seu passado, recapitulando todas as violências das quais tinha sido vítima desde a 


\section{RevistAleph}

infância. Dentre as quais, narrada com detalhes perturbadores, uma operação cirúrgica que sofrera sem anestesia quando era pequena, insistindo na dor incomensurável que sentira. Mergulhados na avalanche de seus relatos forjados de sangue, golpes e gritos, não fomos capazes de fazê-la parar. Estávamos congelados, paralisados, perdidos em um tipo de 'fora do tempo traumático' e não percebemos que haviam-se passado duas horas e meia, até que a secretária veio nos dizer que a Instituição ia fechar. Ruslana pediu para nos ver no dia seguinte e fiquei surpreso comigo mesmo quando respondi: "Amanhã trabalho com pedopsiquiatria; nos outros dias, sabe, trabalho com crianças". Confidência estranha para um terapeuta, ainda mais que tal explicação era endereçada a uma paciente agitada por impulsos infanticidas.

À noite, constatamos que tínhamos os gânglios linfáticos inchados ao redor da zona em que Ruslana localizara a dor ressentida durante sua cirurgia. Tínhamos, em nosso corpo, os traços da invasão sofrida pela paciente e desconfiamos que isto tinha relação com os eventos relatados em sessão e com as associações que a levaram a seu passado e sua "péssima mãe" e trazia uma violência primária não psíquica. Tratava-se, certamente, dos elementos beta não transformados em elementos alfa (Bion, 1962) e, por consequência, paralisados e presos no corpo da paciente, que nos levara por sua regressão vertiginosa a fases muito precoces da relação mãe/bebê. Não armado da capacidade de devaneio preconizado por Bion (1962) para metabolizar esses afetos arcaicos arraigados no corpo e alcançados psíquica e fisicamente, ficamos presos em um ódio contratransferencial. Este experimento, indissociável do nosso amor ${ }^{55}$ por Ruslana, foi seguido por questões projetivas/introjetivas dessa comunicação primitiva surgida de maneira inesperada, quando fizemos referência ao que ela mais detestava: crianças. Foi, posteriormente, que apreendemos essa dimensão econômica da contratransferência acumulação de tensão excitante não vinculada ao pensamento - , cujo desconhecimento provoca a descarga, segundo a advertência de Fédida (1992), corroborado pela experiência que acabamos de evocar neste momento. Ser o

\footnotetext{
55 Winnicott (1947, p. 74) mostrou que a coincidência de amor e ódio se encontra, de forma paroxística, na análise de alguns pacientes psicóticos e "implica que, no histórico do paciente, houve uma carência do ambiente, no momento das primeiras pulsações instintivas, na busca do objeto".
} 


\section{RevistAleph}

receptáculo da violência de Ruslana era o maior desafio durante as sessões ${ }^{56}$. Pareceunos que assegurar uma escuta receptiva e passiva era o ideal em seu caso, pois endossar um papel mais "penetrante" poderia provocar um ataque traumático em sua história. Assim, todas as vezes em que tentamos interpretar seus enunciados, Ihe oferecendo ligações entre os eventos de seu passado e seus atos ou ressentimentos atuais, acabamos colidindo com um muro silencioso. Além do mais, quando tentamos colocar em questão sua busca por uma identidade transgênero, que só constituía uma rejeição decididamente defensiva do feminino nela, uma escapatória e uma certa dificuldade de ser, não fomos ouvidos. Sob esse ponto de vista, o trabalho terapêutico não consistia em tentar levar a paciente além dessa conduta de 'evitamento', pela conscientização dos processos que tinham contribuído para seu surgimento. Teríamos, eventualmente, focado em tal objetivo, se a paciente tivesse manifestado a mínima intenção de se engajar em um trabalho de elaboração. De nosso ponto de vista, o que Ruslana buscava, antes de tudo, era que um Outro assumisse sua história traumática e se fizesse testemunha dos sofrimentos e agressões sofridas por ela. Sabe-se que as vítimas precisam que a justiça reconheça que elas foram martirizadas, para que, em seguida, possam se tratar. Nossa paciente não chegou a ponto de identificar seus torturadores, como é, frequentemente, o caso, por causa do véu do recalcamento ou do muro armado de clivagens. Ela tinha perfeito conhecimento disso, com exceção de seu avô abusivo que continuava sendo uma figura idealizada, seu único apoio narcísico, em um mundo objetivo profanado e contaminado. Por fim, o papel do terapeuta consistia, ao que nos parece, em acolher sua fala morta, acompanhar sua viagem até o abismo e à "sobrevivência" após essa longa viagem, de forma a fazer Ruslana reconhecer que tinha também sobrevivido.

\footnotetext{
${ }^{56}$ Este constitui um dos tipos de transferências identificados por Pontalis $(1975$, p. 83), ao longo do qual o terapeuta "se sente muito incluso, invadido, bombardeado por um excesso de euforias" e se torna "depósito" da violência pulsional do paciente.
} 


\section{RevistAleph}

\section{Da transculturalidade à trans-sexualidade: o meta-âmbito institucional}

É significativo que a Instituição na qual recebemos Ruslana constitui uma mistura de cultura, tanto identitária e sexual, como de língua e cultura. E, mesmo se as pessoas que frequentam esse lugar insistem na visão geral de diversidade de gêneros, deixando-os à vontade imediatamente, temos podido identificar uma pré-transferência positiva incentivada por esse ambiente de transidentidade generalizada.

Moro (1998) destacou a importância da descentralização, a saber, a exigência para os cuidadores de se descentralizar de seu meio de origem, a fim de acolher "outras" problemáticas e controlar sua contratransferência cultural (preconceitos raciais, religiosos, colonialistas, sexistas, etc.). Em seu ponto de vista, Sironi (2011), adotando uma perspectiva um pouco distante daquela de Butler (2009), que compara o exílio geográfico a uma expatriação do regime dominante de gênero, postulando a criação de um centro melancólico na origem do poder de agir, concebe "os mestiços de gêneros" como fonte de riqueza, expressão da multiplicidade em si e instrumento intrapsíquico do que está se desenvolvendo atualmente no nível coletivo, a saber, o surgimento de subjetividades originais, graças às migrações planetárias, às misturas culturais e às adoções internacionais. Buttler traz, assim, o transgenerismo ao paradigma do transcultural e à cena clínica, colocando, em paralelo, reações transferenciais associadas à cultura e àquelas conectadas ao gênero.

Lembraremos, aqui, o romance de Jeffrey Eugenides (2002), Middlesex, que destaca a hibridação de gênero e etnia, através do perfil de um personagem homem trans de origem mestiça, que se compara a um emigrado, na angústia de ser desmascarado por seus compatriotas, quando passa por pessoas pertencentes a seu gênero anterior. Outro exemplo: o filme de David Cronenberg (1993) M. Butterfly, que sobrepõe engenhosamente o amor de um diplomata francês por uma asiática transgênero e a subjugação do Oriente em um Ocidente imperialista. A transformação do homem ocidental em cantora chinesa, após a ruptura de sua relação erótica, alegorizando a incorporação melancólica do objeto perdido, ilustra claramente a 


\section{RevistAleph}

permeabilidade das categorias identitárias do gênero e da raça ${ }^{57}$. Sendo estrangeiro e dotado de uma tripla cultura, nossas experiências de descentralização e mestiçagem trabalham efetivamente em favor de uma transferência/contratransferência positiva com os expatriados e mestiços de gêneros, no interior de um meta-âmbito institucional, que oferece um verdadeiro apoio a essas pessoas fragilizadas pela tirania de ideais normativos. Apesar disso, o trabalho insidioso das normas não ameaça nem os terapeutas, nem os que sofrem por causa deles. A violência de gêneros prescrita produz a violência. É assim que podemos apreender as 'provas' que alguns de nossos pacientes trans nos fazem suportar, tornando pública uma curiosidade intrusiva a respeito de nossa vida privada. Nossa recusa em satisfazer a curiosidade deles foi, evidentemente, ditada por nosso desejo de permanecermos neutros. Paul Denis (2013, p. 765-766), que aborda esta questão de maneira freudiana, escreve:

É preciso considerar que a neutralidade da análise se estende a seu papel de suporte de projeção: características muito avançadas podem, de fato, limitar a projeção de todo um registro de relações, desviar as imagens projetadas ou privilegiar algumas outras. (...) Um analista que torna público suas preferências de gênero, em um sentido ou em outro, limita as possibilidades de expressão de seu paciente e vive, apesar dele, como quem prescreve uma atitude.

Por querer muito proteger essa abstenção da prescrição de atitudes de gênero, finalmente pervertemos nossa neutralidade. As projeções sobre nós e as solicitações sexuais eram tão frequentes e grandes, que chegamos a alterar nosso comportamento usual. Comentários do tipo: "Você parece muito magra [a entender: castrada] quando se barbeia", "Já que você não diz se é solteiro, não venho uma segunda vez", "Diga-me quem você é, isso vai me tranquilizar" nos deixavam perplexos, confusos ou irritados, ainda mais porque, na sessão, alguns trans FtM nos falavam sobre o membro viril que tinham percebido examinando as dobras de nossa calça ao nível da virilha, enquanto as mulheres trans $M t F$ nos olhavam de maneira semelhante, estimuladas por uma luxúria sem filtro. Às vezes, como não é de costume para um terapeuta, nosso corpo valia muito mais do que nossa palavra, e isso era doloroso. Então, colocávamos algumas roupas

\footnotetext{
${ }^{57}$ Ler-se-á, sobre este assunto, a análise apaixonante de Teresa De Laurentis (1999).
} 


\section{RevistAleph}

escuras, "esquecíamos" de fazer a barba para evitar de perder nossos "atributos fálicos", ou adotávamos posturas do tipo pernas amplamente abertas e firmemente apoiadas no chão, para corresponder radicalmente aos traços do macho estereotipado que nossos pacientes projetavam em nós.

Compreendemos, finalmente, que reproduzíamos defensivamente a identificação quanto às normas de gênero, que uma parte da população trans incorporara pela violência, e que estávamos vivendo através dos diversos comentários existentes e da incitação forçada a uma autodefinição. Por outro lado, a consciência disso não distanciou automaticamente nossa vergonha, pois, como aponta Pontalis (1975, p. 75), reconhecer a contratransferência não implica obrigatoriamente em se libertar dela,

(...) porque a resistência à contratransferência está também presente no "eu sei onde estou", e que ela seria analisada no analista pelo seu exemplo de transferência "maternal", para conter e ter sob o jugo da palavra e da imagem emoções inacreditáveis.

Este alerta sugere a necessidade de aplicar, na contratransferência, o que Freud (1914) preconizou, pensando nos pacientes: o trabalho através de suas resistências. Importaria para o terapeuta, finalmente, cumprir, de maneira análoga à do paciente, uma travessia de seus fantasmas e trabalhar constantemente a divergência de seus preconceitos clínicos, teóricos, socioculturais e "transexuais", no sentido que Nahon (2006, p 23) dá a este termo:

(...) a subdivisão das identidades em vigor no inconsciente, sua combinação extrema, essa programação muito singular do masculino e feminino, que transparece nas formações do sonho. A transsexualidade desloca, distorce e difrata o sexo, fixando-a em suas representações, onde prima, evidentemente, a ideia de uma "sexualidade do homem" e de uma "sexualidade da mulher", a fortiori, a heterossexualidade e a homossexualidade.

\section{À GUISA DE CONCLUSÃO}

Como vimos, Ruslana, assim como outros pacientes, homens trans ou mulheres trans que encontramos, testemunhou com veemência sobre o abuso de medicamento 


\section{RevistAleph}

ou abuso psicológico dos profissionais da saúde mental, assim como o caráter iatrogênico de algumas instituições/dispositivos. Podemos ignorar o impacto dessas suscetíveis "violências secundárias" reativando a violência primária evocada acima e produzindo uma conjuntura traumática acionando uma descompensação? A nosso ver, seria clinicamente perigoso apreender um colapso dessa ordem como um distúrbio psiquiátrico e imputá-lo ao transgenerismo. Como afirma Benslama (2004, p. 26) a respeito do exílio - compreendemos os transgêneros como expatriado.a.s de sua cultura original de gênero -, assim como Eugenides (2002), Butler (2009) ou Sironi (2011):

(...) o amálgama de uma série de eventos em benefício de um entre eles ou do último que se encontra de alguma forma carregado com o máximo de "malus" traumático, que elimine a questão específica da psicanálise. Ele o anuncia da seguinte maneira: "O que faz evento para um assunto?

Comentaremos de maneira similar a narrativa fictícia, pré-fabricada, ensinada pelos "dramaturgos do transexualismo médico" (Butler, 2006), que deve ser desenvolvida, para bem ou mal, por dois anos, a fim de atingir o sésamo dos protocolos de cuidados nos centros especializados, na França. Trata-se, ainda, de uma outra forma de violência apta a perverter "a identidade narrativa" (Ricoeur, 1990) dos assuntos transgêneros e a excluir sua capacidade de historicização. Lembraremos que essas alterações socialmente induzidas ${ }^{58}$ são, muitas vezes, apreendidas em uma lógica de inversão ${ }^{59}$ como fracasso inerente às transidentidades. Quanto à rigidez observada na estruturação psíquica dos trans (Lothstein, 1983), não se considerou que ela pudesse, na ocasião, ser fruto da violência remetida por esses dispositivos/instituições? O clínico analítico não esquece, no entanto, que o diagnóstico é parte integrante da relação transferencial, a mesma assumida na transferência para o meta-âmbito institucional, cujos efeitos psicopatogênicos foram destacados pelos trabalhos de Oury (1996-97). Se o "escudo terapêutico" oficial "constitui uma ação de ortopedia social que se ignora",

\footnotetext{
${ }^{58} \mathrm{Cf}$. a pesquisa especializada sobre "Narrativa Transexual Estilizada", realizada por Hughes (2018).

${ }^{59}$ Delcourt (2016, p. 90) é um dos raros psicanalistas franceses a falar de "um problema psíquico, não como fator contribuindo para a flutuação da identidade, mas como uma consequência do trans transformado em dis por causa das normas sociais.
} 


\section{RevistAleph}

como afirma, na veia foucauldiana, Espineira (2011, p. 200), pois esse "trata de trans dóceis e úteis à sociedade" que reafirmam a binariedade instituída de gêneros, um segundo escudo, dessa vez jurídico, provocava, até abril de 2017, uma violência suplementar, uma vez que o direito francês condicionava a retificação do estado civil a uma redesignação sexual e uma esterilização obrigatória, "solução eugênica", ilustrando que "o sexo não é só uma categoria biológica, mas também estatal" (Fassin, 2011). Vale mencionar, aqui, que metade dos transgêneros que recebemos nas sessões teria desejado poder mudar de identidade legal sem passar por uma cirurgia. Alguns demonstraram verdadeira aflição entre o apego a seus órgãos e a pressão exercida pelos "costumes açougueiros" (Delcourt, 2016, p. 90) em vigor, para que eles/elas os sacrificassem em nome de uma nova certidão de nascimento. É no contexto de todas essas dificuldades acumuladas que propomos a declaração "a violência move o homem", para resumir nossa reflexão. O "homem" conota o caráter sacralizado da imagem do macho, que fascina um grande número de $F t M$, fruto de investimentos e contra investimentos de imagos parentais sobrepostos e "misturados" aos idealismos normativos incorporados. O "move" faz referência à pulsão interna que agita esses sujeitos, mas, também, à pressão externa, pois as identificações, que não constituem a prerrogativa das interpretações metapsicológicas, surgem de uma lógica intrapsíquica. Mas são, também, reguladas, ou até infiltradas, pelas normas culturais que constituem uma interface entre "dentro" e "fora", de maneira que o gênero possa ser apreendido como conceito limite entre o exterior e o interior, próximo do Eu-Pele ilustrado por Anzieu (1985).

Como escrevem Andreyev \& Neau (2017, p. 235), “se o Eu é um Eu, antes de tudo, corporal, a linguagem - ferramenta de expressão do Eu - representa essa superfície corporal do psiquismo, a 'pele' do Eu". De nossa parte, entendemos essa linguagem no sentido amplo da semiótica, tal qual o concebe Laplanche (2002) inspirando-se em Jakobson, que tem sua fonte na comunicação primitiva entre o infans e o adulto. Nessa perspectiva, o gênero se revelaria um significante enigmático de assignação, não necessariamente verbal, depositado precocemente pelo outro sobre a superfície corporal do sujeito ou, até para usar a imagem laplanchiana, implantado 


\section{RevistAleph}

como uma farpa sob a pele. Ele constituiria, assim, uma mensagem invariavelmente traumática, suscetível a produzir um efeito de "comoção psíquica" (Ferenczi, 1934), sob o impacto dos "traumas cumulativos" (Khan, 1963) induzidos pelo outro e suas ações fantasmáticas inconscientes.

Definitivamente, defendemos a ideia de que o "move o homem" representa um dos possíveis destinos da violência intrínseca à identificação alóctone do gênero, no caso, uma violência radical, devido a sua conjunção com uma série de intromissões de mensagens e maus tratos e sua dissonância dolorosa com as normas majoritárias. Apropriamo-nos, de maneira despatologizante, do conceito de "move a mulher" que Lacan (1973) emprestou a Antonin Artaud, para fazer dele a marca do delírio schreberiano e o emblema de um gozo totalizante, em oposição ao gozo "não todo" próprio à lógica do significante fálico.

Destaquemos, para terminar, que o crescimento das transidentidades FtM e sua maior visibilidade, hoje em dia (Hansbury, 2005; Peretti, 2009; Sironi, 2011), contribuem para aperfeiçoar e fazer valer o caráter fabricado da identidade masculina, simetricamente ao "mascaramento feminino" (Rivière, 1929), cuja ressonância construtivista suscita menos resistências.

Como afirma Marjorie Garber (citada por Berger, 2013, p. 257), fazendo alusão às fórmulas de sexuação de Lacan, “(...) acontece que a identidade masculina é como a identidade feminina, é da ordem de uma certa encenação, e trata-se de, como se diz em inglês, play a part - "a part" significando ao mesmo tempo o papel e a parte". Assim, essa parte ou partição masculina invalidaria a forte ideia de que somente o "homem" é "todo inteiro" sujeito e tem relação com a "totalidade", enquanto a mulher, permanecendo "parte", continuaria "não toda". 


\section{RevistAleph}

\section{Referências}

ANDREYEV, Z.; NEAU, F. Psychologie clinique et projective. L'adolescent traducteur. vol. 23 (1), p. 223-243. França: Ères, 2017. Disponível em: https://www.cairn.info/revue-psychologieclinique-et-projective-2017-1-page-223.htm?contenu=article

ANZIEU, D. Le Moi-Peau, Nova edição revisada e aumentada. Paris: Dunod, 1995.

AYOUCH, T. L'Évolution psychiatrique. Psychanalyse et transidentités : hétérotopies. vol. 80 (2). p. 303-316. França: ELSEVIER, 2015.

BENSLAMA, F. L'Évolution psychiatrique. Qu'est-ce qu'une clinique de l'exil ?. vol. 69 (1). p. 2330. França. 2004.

BERGER, A. E. Le Grand Théâtre du genre. 1a ed. Paris: Belin, 2013.

BION, W. R. Aux sources de l'expérience. Paris: PUF, 1979.

BUTLER, J. Ces corps qui comptent : De la matérialité et des limites discursives du sexe. vol. 1. Paris: Amsterdam, 2009.

Le Pouvoir des mots : Discours de haine et politique du performatif. vol. 1. Paris: Amsterdam, 2004.

Défaire le genre. vol. 1. Paris: Amsterdam, 2006.

Sexualités, genre et mélancolie : s'entretenir avec Judith Butler. Le transgenre et les "attitudes de révolte". vol. 1. França: Campagne Première, 2009.

CALIFIA, P. Le Mouvement transgenre. 1a ed. Paris: Epel, 2003.

CASTEL, R. Le Psychanalysme. Paris: Flammarion, 1981.

CAULDWELLI, D. O. Sexology. Psychopathia Transsexualis. vol. 16. p. 274-280. E.U.A.: MediMedia Publications, 1949

CHILAND, C. Changer de sexe. vol. 1. Paris: Odile Jacob, 2011.

CRONENBERG, D. Madame. Butterfly. E.U.A.: Geffen Pictures, 1993.

DAVID MÉNARD, M. Sexualités, genre et mélancolie : s'entretenir avec Judith Butler. L'institution des corps vivants selon Judith Butler. vol. 1. p. 197-212. Paris: Campagne Première, 2009.

DELCOURT, T. Insistance. Trans, dys, switch. vol. 12. p. 83-94. França. 2016.

DENIS, P. Revue française de psychanalyse. Transfert et réaction transférentielle de genre. vol. 77(3). p. 762-769. França: PUF, 2013.

DEJOURS, C. Laplanche et la Traduction : une théorie inachevée. Aide à la traduction et assignation de genre. Le Mythosymbolique : Aide ou Obstacle à la traduction ? vol. 1. p. 233248. Paris: PUF, 2018.

ESPINEIRA, K. Le Sujet dans la cité. Le bouclier thérapeutique. vol. 2 (1). p. 189-201. França: Espace Éditorial Le sujet dans la cité, 2011.

EUGENIDES, J. Middlesex. 2a ed. Nova York: Farrar, Straus and Giroux, 2003. 


\section{RevistAleph}

FASSIN, E. Libération. Les leçons inattendues du « mariage trans ». França: 23 de junho de 2011. FÉDIDA, P. Crise et Contre-transfert. vol. 1. Paris: PUF, 2009.

FERENCZI, S. Oeuvres complètes. Réflexions sur le traumatisme. vol. 4. p. 139-147. Paris: PUF, 1982.

FREUD, S. La technique psychanalytique. Remémoration, répétition et perlaboration. p. 117126. Paris: PUF, 2007.

GUILLAUMIN, J. Transfert, Contre-transfert : L’Esprit du Temps. 1a ed. Bordeaux. 1998.

HANSBURY, G. Studies in Gender and Sexuality. The Middle Men: An Introduction to the Transmasculine Identities. vol. 6 (3). p. 241-264. Nova York: Routledge, 2005.

HUGHES, L. Current Debates in the Field of Transsexual Studies: In Transition. Wronging the Right-Body Narrative: On the Universality of Gender Uncertainty. 1a ed. p. 181-193. Nova York: Routledge, 2018.

KHAN, M. The Psychoanalytic Study of the Child. The Concept of Cumulative Trauma. vol. 18 (1). p. 286-306. New york: Routledge,1963.

KLEIN, M. Envie et Gratitude. 1a ed. Paris: Gallimard, 1968.

LACAN, J. Autres Écrits. L'étourdit. 1ạ ed. p. 449-496. Paris: Seuil, 2001.

LAPLANCHE, J. La révolution copernicienne inachevée. Implantation, intromission. vol. 1. p. 355-358. Paris: PUF, 2008.

Sexual : La Sexualité élargie au sens freudien. Les échecs de la traduction. (2000-2006) p. 109-125. Paris: PUF, 2002.

Sexual : La Sexualité élargie au sens freudien. Le genre, le sexe, le sexual. (20002006) p. 153-194. Paris: PUF, 2002.

Sexual : La Sexualité élargie au sens freudien. Trois acceptions du mot " inconscient » dans le cadre de la théorie de la séduction généralisée. (2000-2006) p. 195-214. Paris: PUF, 2002.

LAUFER, L. Cliniques méditerranéennes. Quand dire, c'est exclure. vol. 94 (2). p. 21-36. França: Ères, 2016.

LAURETIS, T. Journal of Women in Culture and Society. Popular Culture, Public and Private Fantasies: Feminity and Fetishism in David Cronenberg's « M. Butterfly ». vol. 24(2). p. 303-334. E.U.A.: The University of Chicago Press, 1999.

LEBOVICI, S. Psychopathologie du bébé. vol. 1. Paris: PUF, 1989.

LE POULICHET, S. Les Chimères du corps. vol. 1. Paris: Aubier, 2010.

LOTHSTEIN, L. M. Female-to-Male Transsexualisme. 1ạ ed. Nova York: Routledge, 1983.

MORO, M. R. Psychothérapie transculturelle de l'enfant et de l'adolescent. 1a ed. Paris: Dunod, 1998.

NAHON, C. Cliniques méditerranéennes. La trans-sexualité ou l'en-dehors des formes. vol. 74. p. 5-26. França: Ėres, 2006. 


\section{RevistAleph}

OURY, J. Les Séminaires de la Borde. Nîmes: Champ social, 1998.

OVIDE. Les Métamorphoses. Paris: Actes Sud, 2001.

PERETTI, M. L. Le Transsexualisme, une manière d'être au monde. vol. 1. Paris: L'Harmattan, 2009.

PONTALIS, J.B. Nouvelle Revue de psychanalyse. À partir du contre-transfert : le mort et le vif entrelacés. vol. 12. p. 73-88. Paris: Ères,1975.

RICOEUR, P. Soi-même comme un autre. 1a ed. Paris: Seuil, 1990.

RIVIÈRE, J. Féminité mascarade. La féminité en tant que mascarade. vol.1. p. 197-214. Paris: Seuil, 1994.

SÉNAC, R. Quel genre de sexe. Être juste avec les études de genre : au-delà d'un rendez-vous manqué. vol. 1. p. 69-92. Paris: PUF, 2017.

SIRONI, F. Psychologie(s) des transsexuels et des transgenres. vol. 1. Paris: Odile Jacob, 2011.

WINNICOTT, D.W. De la pédiatrie à la psychanalyse. La haine dans le contretransfert. vol. 1. p. 72-82. Paris: Payot, 1969.

La crainte de l'effondrement. vol. 1. p. 205-216. Paris: Gallimard, 2000.

Traduzido por Mônica Fiuza BF (coordenadora do Labestrad/setor de francês), Rafael Rodrigues e Thainá Carungaba, no LABESTRAD/UFF, outubro de 2019.

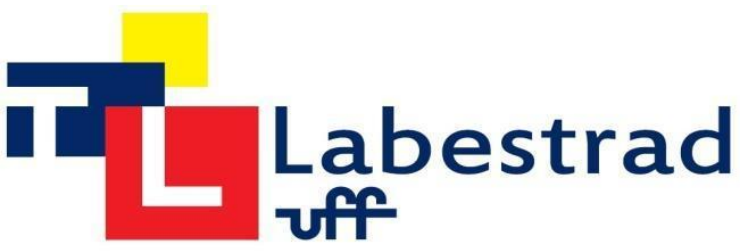

